\title{
Comparative Pulmonary Protective Efficacy of Amifostine and it's Analogue S-2(2-aminoethylamino)ethyl Phenyl Sulfide (DRDE-07) against Sulphur Mustard Induced Oxidative Stress and Inflammation in Female Mice
}

\author{
Alok Kumar Soni' ${ }^{1}$ Uma Pathak², Durga Prasad Nagar' ${ }^{1}$, Arvind Kumar Gupta ${ }^{3}$, Gurusamy Mathu Kannan ${ }^{1, *}$ \\ 'Division of Pharmacology and Toxicology, Defence Research and Development Establishment, Gwalior, Madhya Pradesh, INDIA. \\ 2Division of Synthetic Chemistry, Defence Research and Development Establishment, Gwalior, Madhya Pradesh, INDIA. \\ 3Process Technology Development Division, Defence Research and Development Establishment, Gwalior, Madhya Pradesh, INDIA.
}

\begin{abstract}
Aim: The present study was undertaken to investigate the comparative pulmonary protective efficacy of Amifostine (S-2[3-aminoprophylamino] ethyl phosphorothioate) and its analogues DRDE-07 (S-2(2-aminoethylamino) ethyl phenyl sulfide) against sulfur mustard toxicity in mice. Materials and Methods: Twenty female mice were divided into four groups: Control, SM group animals were percutaneously exposed to $16.2 \mathrm{mg} / \mathrm{kg}$. The third and fourth group of animals received amifostine and DRDE-07 (210 and 250 $\mathrm{mg} / \mathrm{kg}$ respectively) through the oral route, $30 \mathrm{~min}$ before SM exposure. The clinical symptoms and body weight changes were observed daily and sacrificed on $7^{\text {th }}$ day. Bronchoalveolar lavage fluid (BALF) and lung tissue were collected for biochemical and histopathological studies. The following biochemical endpoints were studied in BALF (total cell count, lactate dehydrogenase, protein content, $\beta$-glucuronidase activity, MMP-2, 9 activity and $\mathrm{FSH}$ ) whereas reactive oxygen species (ROS), reduced glutathione (GSH), lipid peroxidation, superoxide dismutase, catalase and myeloperoxidase activity was measured in lung tissue. The above biochemical observations are also supported by histopathology studies. Results: Dermal exposure to SM significantly reduced body weight. The significant increase in BALF LDH leakage, protein content, cell number and MMPs activity in the SM exposed animals suggest disruption of endothelial barrier in the
\end{abstract}

lung ( $p<0.05)$. Significant ROS generation $(p<0.05)$ was observed in lung tissue of SM group which results in a significant decrease in SOD GSH and CAT and an increase in MDA $(p<0.05)$. These alterations in BALF as well in lung tissue due to SM exposure was significantly prevented by the pretreatment of amifostine and DRDE-07 $(p<0.05)$. The histopathological observations also support the above results. The above results indicate that the preventive efficacy of DRDE-07 is better than amifostine. Conclusion: The percutaneous SM exposure-induced pulmonary damages were significantly protected by DRDE-07 than amifostine in mice.

Keywords: Amifostine, BALF, Chemical Warfare Agents, DRDE-07, Pulmonary injury, Oxidative stress, Sulfur mustard.

\section{Correspondence}

Dr. Gurusamy Mathu Kannan

Division of Pharmacology and Toxicology, Defence Research and Development Establishment, Jhansi Road, Gwalior - 474 002, Madhya Pradesh, INDIA.

Phone no: +91-0751-2390369

Email: gmkannan@drde.drdo.in

DOI: 10.5530/ijpi.2020.1.7

\section{INTRODUCTION}

Sulfur mustard (SM, 2, 2'-dichlorodiethyl sulfide) is a vesicant chemical warfare agent which was widely used during World War-I, Iran-Iraq conflicts and recently by the Syrian terrorist groups. ${ }^{1}$ Skin, eye and respiratory system are the major target organs to SM exposure and induce a small blister to severe pathological alteration and even death. ${ }^{2}$ Even single exposure to mustard gas with respiratory injury was associated with increased risk of lung cancer in later life. ${ }^{3}$ Because of the lipophilicity nature, SM penetrates the human skin and distributed to the whole body within a short time, where they induced internal organs injury. Vijayaraghavan et al. (2001) demonstrated that SM is highly toxic through the dermal route than subcutaneous and oral route. ${ }^{4}$ Recently, Mohamed Batal et al also reported that percutaneous SM exposure induces time and dose-dependent DNA damage in internal organs and lung was the most affected organ. ${ }^{5}$ Oxidative stress and inflammations are attributed to the SM induced pulmonary toxicity in various experimental animals. ${ }^{6}$ The subcutaneous injection of half mustard induced oxidative stress through free radical generation and activation of the immune system through the infiltration of $\mathrm{T}$ cells and generation of inflammatory cytokines which are responsible for toxic effects in the lungs. ${ }^{7.8}$ Various strategies have been adopted to counteract the SM toxicities which include administration of antioxidant, anti-inflammatory agents, protease inhibitors and radio protector. ${ }^{9}$ Treatment by antioxidant and anti-inflammatory agents have been reported for SM induced systemic injury include such as melatonin, pentoxifylline, $\mathrm{N}$-acetyl cysteine, sodium thiosulphate. ${ }^{10,11}$ But none of them found to be effective in preventing the SM induced lethal toxicity.

Amifostine (WR-2721) is an analogue of cysteamine and selectively protect the normal tissues from the toxicities associated with chemotherapy and irradiation. ${ }^{12}$ The cytoprotective properties of amifostine are attributed to the potent scavenging of drug or radiation-induced oxygen free radicals. ${ }^{11}$ Since the SM toxicity mimics the radiation toxicity the prophylactic efficacy of amifostine was tested against SM both in vitro ${ }^{13}$ and in vivo. ${ }^{14} \mathrm{Few}$ studies were also compared to the protective efficacy of amifostine and DRDE-07 on different animal models against SM and nitrogen mustard. ${ }^{15,16}$ Though the above studies suggested the better prophylactic efficacy of DRDE-07 than amifostine, on haematological, hepatic and renal biochemical parameters, there is no report on the pulmonary protection. The present study was aimed to investigate 
the comparative pulmonary protective efficacy of amifostine and DRDE07 against SM induced toxicity in mice. In the present study, the focus was mainly on the SM induced biochemical changes in BALF and lung tissue and its modulation by pretreatment of amifostine and DRDE-07. The BALF and lung tissue oxidative stress and inflammatory biochemical endpoints were studied along with histopathological analysis.

\section{MATERIALS AND METHODS}

\section{Chemicals}

Amifostine and DRDE-07 S-2(2-aminoethylamino) ethyl Phenyl Sulfide were synthesized in Synthetic Chemistry division of DRDE and characterized by elemental analysis, IR, ${ }^{1} \mathrm{HNMR}$ and mass spectral analysis. SM was also synthesized in the declared facility of DRDE and was found to be 99 \% pure by TLC. LDH kit was purchased from Tulip Coral Clinical System, India. Phosphate buffer saline, Reduced glutathione, Dithiobis 2 -nitrobenzoic acid (DTNB), Ethylenediaminetetraacetic acid (EDTA), Trichloroacetic acid (TCA), PEG-300, Trizma, Sodium dodecyl sulfate (SDS), 1,1,3,3-Tetra ethoxy propane (TEP), Pthalaldehyde were purchased from Sigma-Aldrich Co. (St. Louis, MO). All other chemicals of extra pure grade were purchased from Merck (Mumbai, India).

\section{Animals and treatment}

Randomly bred female Swiss mice $(23 \pm 2 \mathrm{~g})$ were obtained from Establishment animal facilities. All animals were housed in polypropylene cages with free access to feed (Ashirwad laboratory, Chandigarh, India.) and tap water. Twenty four hours before SM topical exposure, hairs on the dorsal side of the animals were closely clipped using a pair of scissors. Twenty hair clipped animals were randomly distributed into following four groups containing 5 animals in each. $\mathrm{LD}_{50}$ of $\mathrm{SM}$ was determined in a previous study by the moving average method ${ }^{17}$ using three to four groups, each group consisting of four animals. ${ }^{14}$

Group I: Control, only PEG-300 was applied on hair clipped back of animals.

Group II: SM was dissolved in the PEG-300 (final dose $16.2 \mathrm{mg} / \mathrm{kg}$, which is equivalent to $2 \mathrm{LD}_{50}$ through percutaneous route) and then uniformly applied on hair clipped back of animals.

Group III: Amifostine (210 mg/kg) was given orally, $30 \mathrm{~min}$ before SM application

Group IV: DRDE-07 (250 mg/kg) was given orally, 30 min before SM application

The above experiments were conducted in a fume cupboard with highspeed exhaust facilities. The clinical symptoms and body weight changes were observed for seven days. On day 7 the animals were sacrificed, BALF and lung tissue were collected for biochemical and histopathological studies. The experimental details are depicted as Figure 1. The above experimental protocol was approved by the Institutional Animal Ethical Committee (IAEC) and Control and Supervision of Experiments on Animals (CPCSEA) Ministry of Fisheries, Animal Husbandry and Dairying, Department of Animal Husbandry and Dairying, Government of India.

\section{Collection of bronchoalveolar lavage fluid}

At day 7, animals were sacrificed and BALF was collected as per the procedure described previously. ${ }^{18}$ Briefly, lungs were lavaged with ice-cold, sterile PBS $(1.5 \mathrm{ml})$ via a tracheal cannula secured with thread. This procedure was repeated 5 times using the same fluid and collected in $1.5 \mathrm{ml}$ tube. There was no statistically significant difference in the recovery of bronchoalveolar lavage fluid (BALF) within groups. BALF was immediately centrifuged at $800 \mathrm{~g}$ for $15 \mathrm{~min}\left(4^{\circ} \mathrm{C}\right)$. Supernatants of BALF were frozen at $-80^{\circ} \mathrm{C}$ until analysis. A portion of lung tissue was fixed in $10 \%$ formalin buffer for histopathological studies and remaining was used for biochemical parameters indicative of oxidative stress and inflammation was analyzed by the following methods.

\section{Biochemical assays}

\section{Determination of vascular endothelial damage in lung}

The total protein concentration in BALF was measured using the Pierce BCA protein assay kit (Thermo scientific Rockford, IL). The absorbance was measured at $562 \mathrm{~nm}$, and Proteins were expressed in milligrams protein per millilitre. Bovine serum albumin was used as the standard. Lung epithelium damage was monitored by lactate dehydrogenase (LDH) released in the BALF according to manufacturer's instructions (Ecoline LDH kit from Merk specialities Pvt Ltd, Mumbai) and expressed in U/L. Non-protein sulfhydryl (FSH), in BALF supernatant, was assayed using a slight modification of literature method. ${ }^{19}$ Briefly, $0.1 \mathrm{ml}$ supernatant was mixed in $0.1 \mathrm{ml}$ of $10 \%(\mathrm{w} / \mathrm{v})$ Trichloroacetic acid and centrifuged at $3000 \mathrm{~g}$ for $15 \mathrm{mins}$ at $4^{\circ} \mathrm{C}$ condition. $0.1 \mathrm{ml}$ of the supernatant fraction was diluted with $0.9 \mathrm{ml}$ of phosphate buffer $(0.1 \mathrm{M} \mathrm{pH} 8.2)$ and further treated with $20 \mu \mathrm{l}$ of DTNB $(10 \mathrm{mM}$ in methanol) then the concentration of FSH was calculated using absorbance at $412 \mathrm{~nm}$.

\section{Measurement of oxidative stress biomarkers in lung tissue}

Oxidative stress biomarkers were assayed in lung tissue homogenate $(10 \%, \mathrm{w} / \mathrm{v})$ which was prepared in ice-cold $1.15 \% \mathrm{KCl}$, using a glass homogenizer. Subsequently, the homogenate was centrifuged at 10000 $\times \mathrm{g}$ for $30 \mathrm{~min}$ at $4^{\circ} \mathrm{C}$ and the supernatant was collected. Level of reactive oxygen species (ROS) was measured using the method of Gupta et al. ${ }^{20}$ Lipid peroxidation was measured as thiobarbituric acid reactive substances by modified Okhawa method as described earlier. ${ }^{21}$ Briefly, $400 \mu \mathrm{l}$ of tissue homogenate sample was mixed with $400 \mu \mathrm{l}$ TCA (15\%) for protein precipitation and then centrifuged at $2000 \mathrm{~g}$ for $15 \mathrm{~min}$ at the $4^{\circ} \mathrm{C}$. The supernatant was taken into a tube containing $40 \mu \mathrm{l}$ of TBA $(0.8 \%)$ and $160 \mu \mathrm{l}$ of distilled water. Reaction mixture further heated for $1 \mathrm{hr}$ at $95^{\circ} \mathrm{C}$ and then cooled. Finally, absorbance was measured and expressed in $\mathrm{nmol} / \mathrm{g}$ of tissues. Tissue reduced glutathione concentrations were assayed using the Ellman method. ${ }^{22}$ Briefly, $200 \mu \mathrm{l}$ homogenate supernatant was mixed with an equal volume of $10 \%$ TCA to precipitate protein. After centrifugation for $10 \mathrm{~min}, 0.8 \mathrm{ml}$ phosphate buffer solution $(0.1 \mathrm{M})$ was added to $200 \mu \mathrm{l}$ of supernatant and finally, $50 \mu \mathrm{l}$ of DTNB $(10 \mathrm{mM})$ added to the reaction mixture and absorbance was recorded at $412 \mathrm{~nm}$. Superoxide dismutase (SOD) activity was determined by the method Marklund and Marklund. ${ }^{23}$ Briefly, $20 \mu \mathrm{l}$ of homogenate was mixed with $200 \mu \mathrm{l}$ Tris-EDTA buffer ( $\mathrm{pH}$ 8.2) then $50 \mu \mathrm{l}$ of pyrogallol (0.2 $\mathrm{Mm} \mathrm{pH} \mathrm{6.5)} \mathrm{was} \mathrm{added.} \mathrm{Immediately,} \mathrm{the} \mathrm{kinetics} \mathrm{of} \mathrm{this} \mathrm{mixture}$ was read at $420 \mathrm{~nm}$ for $1 \mathrm{~min}$. SOD was expressed in unit/ml where one unit of SOD activity defined as the amount of enzyme required for $50 \%$ inhibition of pyrogallol autoxidation. Catalase activity was determined using method of Beer and Seizer (1952). ${ }^{24}$ Briefly, $20 \mu$ of sample supernatant was mixed with $200 \mu \mathrm{l}$ of phosphate buffer at pH 7.4 and finally, $50 \mu \mathrm{l}$ of hydrogen peroxide $(0.11 \mathrm{Mm})$ added and absorbance was taken at $240 \mathrm{~nm}$.

\section{Biochemical analysis of inflammatory parameters in BALF}

$\beta$-Glucuronidase activity in BALF was determined according to the method of Fishman et al. ${ }^{25}$ Approximately $0.1 \mathrm{ml}$ of sodium acetate buffer $(0.2 \mathrm{M} \mathrm{pH} 4.5)$ mixed with $0.1 \mathrm{ml}$ of $6 \mathrm{mM}$ phenolphthalein mono-bD-glucosiduronic acid as substrate then $0.05 \mathrm{ml}$ of BALF supernatant added and incubated for $4 \mathrm{hr}$ at $37^{\circ} \mathrm{C}$. Further $0.75 \mathrm{ml}$ of distilled water 
and $0.5 \mathrm{ml}$ of glycine $\mathrm{NaOH}$ buffer ( $\mathrm{pH} 11.7$ with $0.2 \%$ SDS) was added and centrifuged at $1500 \mathrm{rpm}$ for $15 \mathrm{~min}$. The absorbance of the reaction mixture measured at $540 \mathrm{~nm}$ to calculate the $\beta$-Glucuronidase activity. To determine the index for neutrophils sequestration in lung tissue, the activity of myeloperoxidase (MPO) was measured by the method of Hirano. ${ }^{26}$ Briefly, $10 \%$ tissue homogenate was prepared in phosphate buffer $(\mathrm{pH}$ 6) containing $0.5 \%$ Hexadecyltrimethylammonium bromide (HTAB). Homogenate was centrifuged at $14000 \mathrm{~g}$ for 30 mins. $20 \mu \mathrm{l}$ of supernatant was added to the $200 \mu$ of reaction buffer $(0.5 \mathrm{M}$ O-dianisidine, $5 \mathrm{Mm}$ phosphate buffer and $0.0005 \%$ Hydrogen peroxide). The kinetic of the reaction was measured at $450 \mathrm{~nm}$ for 15 min using spectrophotometer (Biotek, USA).

\section{Zymography analysis of matrix metalloproteases}

The MMPs are zinc-dependent endopeptidases and can cleave the extracellular matrix components which contribute to the inflammatory cell recruitment, tissue remodelling in the lung. ${ }^{27}$ Expression of MMPs in BALF was detected by zymography using gelatin as a substrate. Briefly, $10 \mu \mathrm{g}$ of BAL proteins were mixed with non-reducing sample buffer and subjected to electrophoresis on $10 \%$ SDS PAGE containing $0.1 \%$ gelatin as substrate. The gels were then incubated with gentle shaking at room temperature in a renaturing buffer for $40 \mathrm{~min}$ followed by incubation in developing buffer at $37^{\circ} \mathrm{C}$ overnight. The gels were stained with simple coomassie brilliant blue staining solution subsequently destained. Finally, the gel was washed in purified water at RT. Gelatinase $(92 \mathrm{kDa})$ activity appeared as clear band on the gel.

\section{Histopathological analysis of lung tissue}

The lung tissues were harvested and fixed in 10\% formaldehyde. The lung tissues were dehydrated with graded alcohol and embedded in paraffin, cut into $5 \mu \mathrm{m}$ thick sections (semi-automated microtome, Leica, Germany). After deparaffinization, tissue sections were stained with hematoxylin and eosin (H\&E) reagent in automated stainer (Leica, Germany). Analysis of stained tissue sections was carried out by light microscopy.

\section{Statistical analysis}

All values are expressed as mean $( \pm$ SEM). Difference between the mean values of normally distributed data was analyzed by using one-way ANOVA followed by Tukey multiple comparisons. The GraphPad Prism 5 software was used (GraphPad Software, CA) for performing analysis and Statistical significance was considered at values of $\mathrm{p}<0.05$

\section{RESULTS}

\section{Preventive effect of amifostine and DRDE-07 on BALF} biochemical variables indicative of endothelial damage

It is now well established that SM exposure leads to alkylation of DNA, proteins, and other membrane components result in impairment of cellular functioning and cell death. Figure 2 represents a significant increase in BALF protein content (76.9 \%), LDH activity (43.8\%) while glutathione level decreased $(37 \%)$ significantly $(p<0.05)$ on day 7 after percutaneous SM exposure as compared to control $(p<0.05)$. However, these alterations were significantly reversed by the pretreatment of amifostine and DRDE-07 $(p<0.05)$. Furthermore, DRDE-07 showed remarkable efficacy over the amifostine.

\section{Preventive effect of amifostine and DRDE-07 on lung inflammation}

Figure 3 shows the activity of myeloperoxidase, $\beta$-glucuronidase, matrix metalloproteases (MMP) and total cell numbers in the BALF. As shown in Figure 3A, the total cell number in BALF was significantly increased in the SM group compared to control $(p<0.05)$. Pretreatment amifostine and DRDE-07 both significantly decreased the BALF cells counts in mice lung 7 days after SM exposure $(p<0.05)$. Figure $3 \mathrm{~B}$ indicates dermal exposure to SM causes significant increases in $\beta$-Glucuronidase activity as compared to control $(p<0.05)$. On the other hand, pretreatment with amifostine reduced the activity and DRDE-07 significantly decreased $(p<0.05) \beta$-Glucuronidase activity over the amifostine. Similarly, Figure $3 \mathrm{C}$ indicates a significantly higher level of MPO activity in the lung tissue of mice after topical SM exposure $(p<0.05)$. These increases were markedly reduced by amifostine treatment. However, MPO activities were significantly lower in DRDE-07 treated animals than those in the SM group at 7 days post-exposure $(p<0.05)$. Sulphur mustard induced both MMP-2 and MMP- 9 and this may persist up to 7 days. Results showed that increased activity of MMP9 was seen in SM exposed group. MMPs activities were evidently reduced by DRDE-07 and amifostine treatment (Figure 3D).

\section{Preventive effect of amifostine and DRDE-07 on lung oxidative stress}

Figure 4 Indicates the increasing of oxidative markers in lung tissue of mice. Dermal exposure to SM significantly induced the increases in ROS (A) level followed by depleted GSH (C) level resulting in significantly increasing lipid peroxidation $(\mathrm{B}, p<0.05)$. Concomitantly to this, decreased SOD and catalase activity also found to be inhibited in the groups exposed with SM (D and E respectively). On the other hand, the amifos-

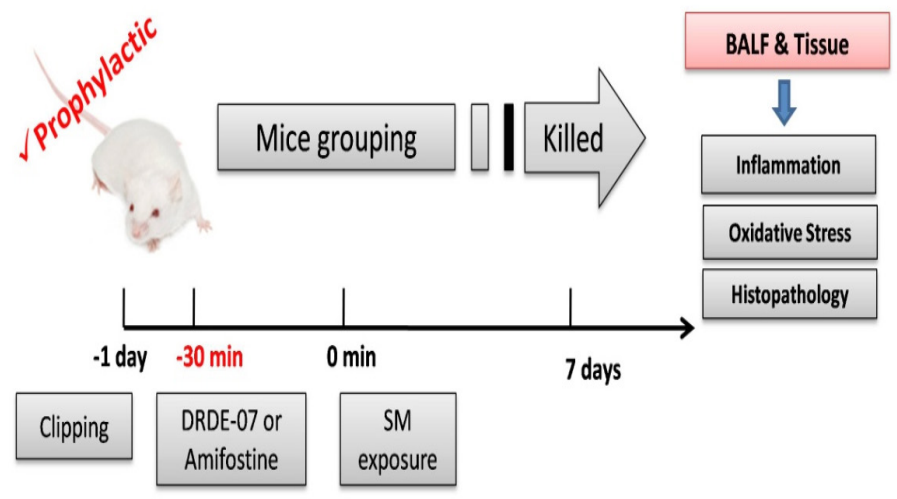

Figure 1: Experimental protocol.
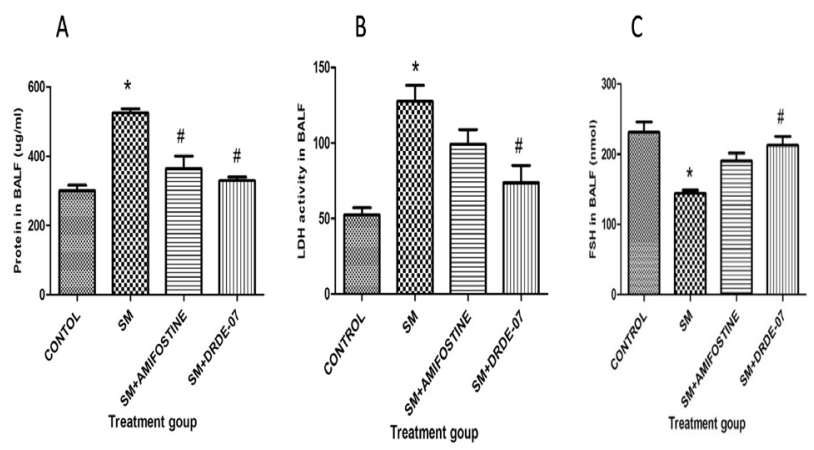

Figure 2: Comparative prophylactic efficacy of Amifostine and DRDE-07 against SM induced toxicity in BALF parameters. (A) Protein concentration. (B) LDH activity and (D) FSH level in BALF. Results are mean \pm SEM of 5 animals per group. ${ }^{*} p<0.05$ compared with control group; $\# p<0.05$ compared with SM exposed group. 


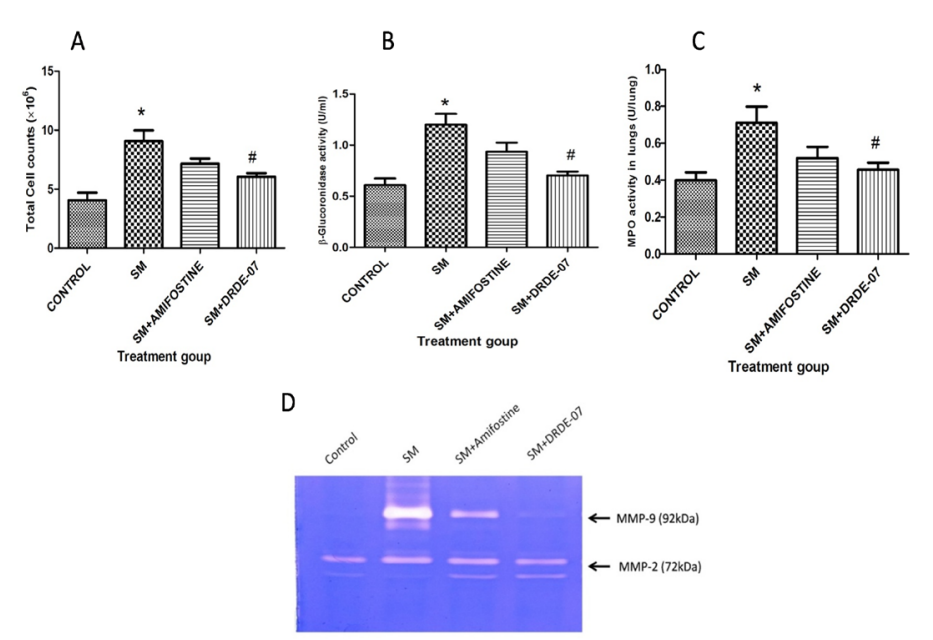

Figure 3: Comparative prophylactic efficacy of pretreatment with amifostine and DRDE-07 on SM induced change in inflammatory biomarkers (A) Total cell counts in BALF MPO (B) $\beta$-glucuronidase activity in BALF (C) activity in lung tissue and (C) Representative image of MMPs (Gelatinase) activity in BALF on Zymograme from 2-3 mice per group. Results are mean \pm SEM of 5 animals per group. ${ }^{*} p<0.05$ compared with control group; $\# p<0.05$ compared with SM exposed group.

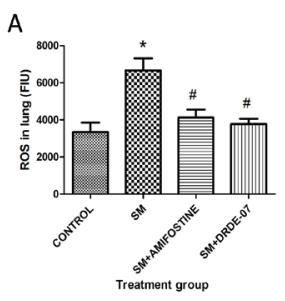

D

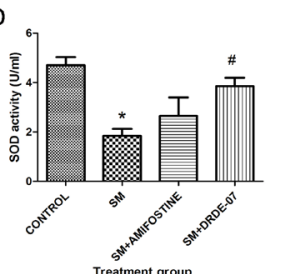

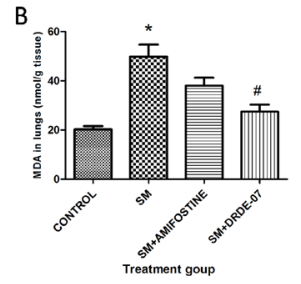

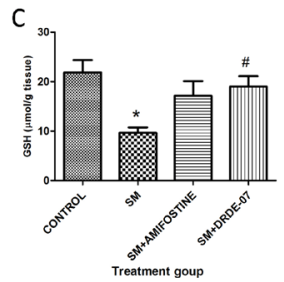

$\mathrm{E}$

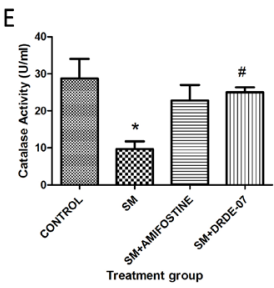

Figure 4: Effect of pretreatment with amifostine and DRDE-07 on oxidative stress markers in lung tissue (A) ROS level in lung tissue, (B) MDA level in lung tissue, (C) level of glutathione content, (D) SOD activity, (E) Catalase activity. Results are mean \pm SEM of 5 animals per group. ${ }^{*} p<0.05$ compared with control group; $\# p<0.05$ compared with SM exposed group.

tine pretreatment decreases the above alteration while the DRDE-07 pretreatment significantly showed protection in all the altered oxidative biochemical variables compared to the SM exposed animals.

\section{Histopathology of lungs}

As shown in Figure 5, the control (A) group shows normal lung architecture without evidence of inflammation or alveolar disruption. While the accumulation of the inflammatory cells into the alveolar space and disruptions of alveolar walls were seen in SM exposed group. However, these pathological alterations were markedly reduced in DRDE-07 treated group. Results suggest that DRDE-07 may inhibit inflammationmediated acute lung toxicity.

\section{DISCUSSION}

Despite a long history of military use, SM remains a threat for both militaries and civilians. Several pathways involved in SM toxicity but the

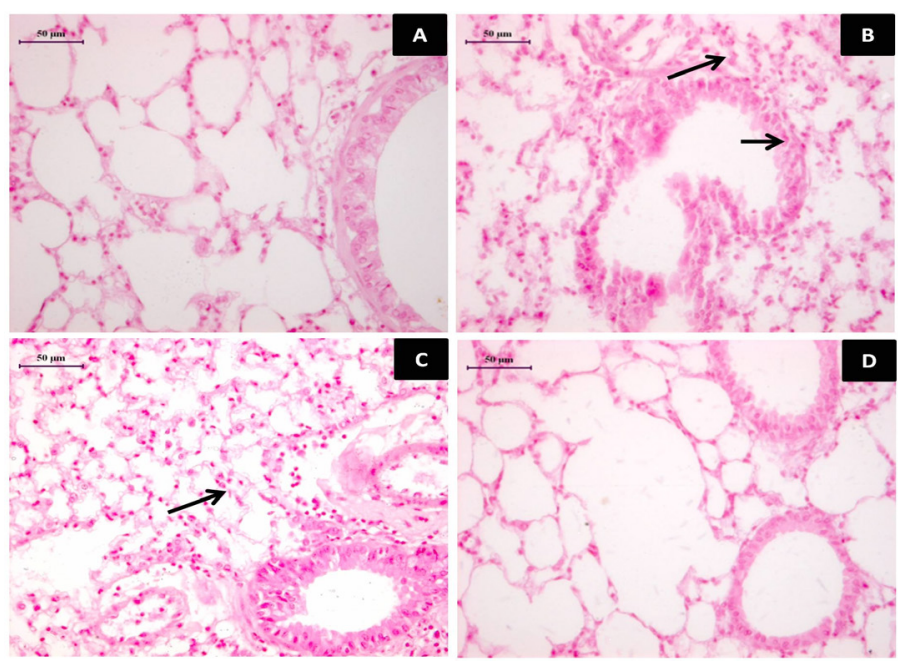

Figure 5: Histological changes after SM in lung tissue and the effect of amifostine and DRDE-07. One representative lung section from 2-3 mice/treatment groups is shown. A: Control group with normal alveoli without any inflammatory cells; B: SM group show bronchial epithelial cell damage and inflammatory cell recruitment (arrow) and thickening of alveolar septa, alveolar damage; C: SM+Amifostine on day 7; D: SM+DRDE-07 on day 7.

widely accepted mechanism is related to its potential alkylation ability to cellular components include proteins, RNA and DNA. ${ }^{28}$ The primary target organs of SM are the eyes, respiratory tract, and skin. However, at high concentrations, SM is also capable of exerting systemic toxicity, leading to death. ${ }^{28,29}$ The previously published report has shown that cutaneous exposure of SM and its analogue not only limited to local injury but also caused a systemic effect. ${ }^{30,31}$ The systemic effect occurs mainly due to the overexpression of inflammatory cytokines, which leads to organ dysfunction resulting in severe body weight $\operatorname{loss}^{31,32}$ In the present study also, a severe decrease in body weight and morphological change were observed which suggest this could be results of intestinal epithelial damage which leads to insufficiency of dietary nutrients. Previously, Batal et al. reported comparative internal organs toxicity after cutaneous exposure of SM and found that lung was the second most affected organ following cutaneous exposure of SM. ${ }^{5}$ Moreover, the SM DNA adducts were more persist in the lungs than the brain and other organs. Yun et al. also reported that the lung of the rat was the most affected tissue after cutaneous exposure of SM..$^{33}$ These all experimental studies support our investigation that demonstrated percutaneously exposure of SM causes significant lung injury, which was supported by biochemical and histopathological changes.

Increase in LDH activity and total protein the BALF has been used as an indicator of cytotoxicity by the variety of compounds including SM. ${ }^{34,35}$ Also in the present study, we have observed an increase in protein content and LDH activity in BALF reflected the lung endothelial damage caused by SM. In addition to that, Myeloperoxidase and $\beta$-glucuronidase are the major constituent of neutrophil cytoplasmic granules and its activity is a direct measure of the neutrophil presence and an indirect indicator of lung injury. ${ }^{36}$ During the neutrophil respiratory burst, MPO produces hypochlorous acid from $\mathrm{H}_{2} \mathrm{O}_{2}$ and chloride ions. In our study prophylactic treatment with amifostine and DRDE-07 significantly reduced the MPO and $\beta$-glucuronidase activity. Besides, our result also supported by an earlier study of Fu et al. (2009), in which amifostine treatment reduced the lipopolysaccharide-induced MPO activity and neutrophil accumulation in the lung parenchyma cells. ${ }^{37}$ Chakrabarti and Pate ${ }^{38}$ demonstrated that the MMP-9 synthesis increased under a variety of physiological and pathological conditions which is responsible for epithelial cell detachment from the basement membrane. In 
addition to that, Calvet et al. (1999) also reported that SM caused increased expression of proteolytic MMPs in lung tissue..$^{39}$ Our results also exhibited a significant increase in gelatinolytic activities particularly MMP-9 in BALF, compared to control animals suggest that these gelatinases are secreted by the inflammatory cells such as macrophages and PMNs. This was further supported by the increasing number of cells in BALF (Figure 3). In the present study, the significant inhibition of MMP9 by DRDE- 07 than amifostine suggest that these compounds may be acting as a protease inhibitor against SM. Previous studies reported that histological changes as well as pathogenic response to SM exposure mainly attributed to the inflammatory cell infiltration and increased number of activated macrophages in BALF. ${ }^{40,41}$ Furthermore, by the use of electron paramagnetic resonance (EPR) and spin trapping techniques, Anderson et al. demonstrate that SM induces ascorbyl radicals in rat lung and this free radical formation was associated with an increase in lipid peroxidation. ${ }^{42}$ Reduced glutathione plays a pivotal role in protecting the lung surface from oxidative attack caused by various factor. ${ }^{43}$ In our study also depletion of GSH was observed after SM exposure. However, pretreatment with amifostine and DRDE-07 demonstrated a significant restoration of GSH and reduction in lipid peroxidation resulting in pulmonary protection against SM toxicity. Various studies on protection mechanism of amifostine have been suggested such as amifostine has superoxide anions and peroxide radical scavenging properties and also likely augmentation of GSH level by providing thiol (SH) pool. ${ }^{44}$ While the protection offered by the DRDE-07 may likely be due to the presence of functional amino group and sulfide group might have help in scavenging SM or its metabolites, thereby reducing SM toxicity in tissues. The better protective efficacy of DRDE-07 over the amifostine may also be attributed due to its analgesic and anti-inflammatory properties. ${ }^{45} \mathrm{Oxi}$ dative stress induced by reactive oxygen species (ROS) and as the result antioxidants depletion is now considered as the major mechanism of SM toxicity on lung injuries. ${ }^{46}$ In our study also we have observed an increase in lung oxidative stress after dermal exposure of SM. The pretreatment of animals with amifostine and DRDE-07 decreased the above altered oxidative biomarkers. SM is a strong mutagenic agent which binds to DNA and leads to cascades of pathological events. ${ }^{28}$ As reported earlier, the protection offered by the amifostine may also be expected due to its binding and detoxify capacity of alkylating agents. ${ }^{47}$ Generation of ROS resulting in the reduction of antioxidant enzyme SOD suggests that a decrease in selective elimination of superoxide radical in dismutation reaction. The reduction of SOD activity is also caused by the high level of cellular peroxides which directly alter its activity. ${ }^{48}$ Results from the present investigation show that DRDE-07 not only improves the glutathione reserve but also resolves the inflammatory changes in animals exposed to SM. Mechanism of protection by DRDE-07 could be due to elevation of GSH and detoxification of SM by up-regulation of cyto-P450 and suppression of inflammatory cytokines. A report also suggested that DRDE07 has promising protective efficacy against SM-induced mutagenicity. ${ }^{49}$ Hence, in this way, it may protect DNA alkylation and NAD depletion and further overcome the toxicity of SM. Although exactly mechanism is not known, further molecular studies are needed to clarify this lacuna.

\section{CONCLUSION}

The percutaneous SM exposure induces oxidative stress and inflammation by depleting the GSH level, ROS generation by the inflammatory cells and secretion of proteases which leads to the structural and functional changes in the lung tissue architecture. In the present study, we have shown that pretreatment of animals with amifostine and its analogues (DRDE-07) significantly reduced the above biochemical alterations. Furthermore, DRDE-07 exhibited more pronounced protection efficacy than amifostine.

\section{ACKNOWLEDGEMENT}

The accession no of this manuscript is DRDE/P\&T/39/2019. The authors are grateful to Dr D.K. Dubey, Director and Dr. R Bhattacharya Head of P\&T division, DRDE Gwalior for their encouragement and support in the present study. Mr. Alok Kumar Soni is the recipient of DRDO Senior Research Fellowship.

\section{CONFLICT OF INTEREST}

The authors declare no competing interest.

\section{ABBREVIATIONS}

SM: Sulfur mustard; BALF: Broncho Alveolar lavage fluid; DRDE-07: S-2(2-aminoethylamino) ethyl phenyl sulfide); MMPs: Matrix Metalloproteases; MPO: myeloperoxidase; LDH: Lactate Dehydrogenase; ROS: Reactive Oxygen Species; TBA: Thiobarbituric Acid; SOD: Superoxide Dismutase; CAT: Catalase; SDS-PAGE: Soduim Dodecyl Sulfate Polyacrylamide Gel Electrophoresis; PMNs: Polymorphonuclear; GSH: Reduced glutathione; Min: Minutes.

\section{REFERENCES}

1. Dacre JC, Goldman M. Toxicology and pharmacology of the chemical warfare agent sulfur mustard. Pharmacol Rev. 1996;48(2):289-326.

2. Balali-mood M, Abdollahi M. Basic and Clinical Toxicology of Mustard Compounds. Basic and Clinical Toxicology of Mustard Compounds. New York: Springer. 2015;75-8

3. Borak J, Sidell FR. Agents of chemical warfare: Sulfur mustard. Ann Emerg Med. 1992;21(3)303-8.

4. Sharma M, Vijayaraghavan R, Ganesan K. Comparison of toxicity of selected mustard agents by percutaneous and subcutaneous routes. Indian J Exp Biol. 2008;46(12):822-30.

5. Batal M, Boudry I, Mouret S, Cléry-Barraud C, Wartelle J, Bérard I, et al. DNA damage in internal organs after cutaneous exposure to sulphur mustard. Toxicol Appl Pharmacol. 2014;278(1):39-44.

6. Tahmasbpour E, Reza ES, Ghanei M, Panahi Y. Role of oxidative stress in sulfur mustard-induced pulmonary injury and antioxidant protection. Inhal Toxicol. 2015;27(13):659-72.

7. Elsayed NM, Omaye ST. Biochemical changes in mouse lung after subcutaneous injection of the sulfur mustard 2-chloroethyl 4-chlorobutyl sulfide. Toxicology. 2004;199(2-3):195-206

8. Mishra NC, March T, Weber W, Benson J, Jaramillo R, Seagrave JC, et al. Sulfur mustard induces immune sensitization in hairless guinea pigs. Int Immunopharmacol. 2010;10(2):193-9.

9. Kehe K, Szinicz L. Medical aspects of sulphur mustard poisoning. Toxicology 2005;214(3):198-209.

10. Sugendran K, Kumar P, Vijayaraghavan R. Treatment for sulphur mustard poisoning: A review. Defence Science Journal. 1998;48(2):155-62.

11. Laskin JD, Black AT, Jan YH, Sinko PJ, Heindel ND, Sunil V, et al. Oxidants and antioxidants in sulfur mustard-induced injury. Ann NY Acad Sci. 2010;1203:92.

12. Capizzi R. Amifostine: The preclinical basis for broad-spectrum selective cytoprotection of normal tissues from cytotoxic therapies. In: Seminars in Oncology. 1996;26(2):3-21.

13. Ohnishi ST, Glick JH, Schein PS. In vitro study on the antioxidant activities of amifostine (WR-2721). Proc Am Assoc Cancer Res. 1992;33:419.

14. Bhattacharya R, Rao PVL, Pant SC, Kumar P, et al. Protective effects of amifostine and its analogues on sulfur mustard toxicity in vitro and in vivo. Toxicol Appl Pharmacol. 2001;176(1):24-33

15. Kumar P, Vijayaraghavan R, Kulkarni AS, Pathak U, Raza SK, Jaiswal DK. In vivo protection by amifostine and DRDE-07 against sulphur mustard toxicity. Hum Exp Toxicol. 2002;21(7):371-6.

16. Kumar P, Gautam A, Prakash CJ, Kumar A, Ganeshan K, Pathak U, et al. Ameliorative effect of DRDE-07 and its analogues on the systemic toxicity of sulphu mustard and nitrogen mustard in rabbit. Hum Exp Toxicol. 2010;29(9):747-55.

17. Gad SC, Wiel CS. Statistics for toxicologists: Principles and methods of toxicology, second edition. New York: Raven Press. 1989;647-67.

18. Kannan GM, Kumar P, Bhaskar ASB, Pathak U, Kumar D, Nagar DP, et al. Prophylactic efficacy of S-2 (2-aminoethylamino) ethyl phenyl sulfide (DRDE-07) against sulfur mustard-induced lung toxicity in mice. Drug Chem Toxicol. 2016;39(2):182-9.

19. Sedlak J, Lindsay RH. Estimation of total, protein-bound, and nonprotein sulfhydryl groups in tissue with Ellman's reagent. Anal Biochem. 1968;25:192-205. 
20. Gupta R, Kannan GM, Sharma M, Flora SJS. Therapeutic effects of Moringa oleifera on arsenic-induced toxicity in rats. Environ Toxicol Pharmacol. 2005;20(3):456-64.

21. Mishra D, Flora S. Differential oxidative stress and DNA damage in rat brain regions and blood following chronic arsenic exposure. Toxicol Ind Health. 2008;24(4):247-56.

22. Ellman GL. Tissue sulfhydryl groups. Archives of Biochemistry and Biophysics. 1959;82(1):70-7.

23. Marklund $S$, Marklund G. Involvement of the superoxide anion radical in the autoxidation of pyrogallol and a convenient assay for superoxide dismutase. Eur J Biochem. 1974;47(3):469-74.

24. Beers RF, Sizer IW. A spectrophotometric method for measuring the breakdown of hydrogen peroxide by catalase. J Biol Chem. 1952;195(1):133-40.

25. Fishman WH, Kato K, Anstiss CL, Green S. Human serum $\beta$-glucuronidase: Its measurement and some of its properties. Clin Chim Acta. 1967;15(3):435-47.

26. Hirano S. Migratory responses of PMN after intraperitoneal and intratracheal administration of lipopolysaccharide. Am J Physiol Cell Mol Physiol. 1996;270(5):836-45.

27. Corbel M, Boichot E, Lagente V. Role of gelatinases MMP-2 and MMP-9 in tissue remodeling following acute lung injury. Brazilian J Med Biol Res. 2000;33(7):749-54

28. Papimeisier B, Gross CL, Petrali JP, Hixson CJ. Pathology produced by sulfur mustard in human skin grafts on athymic nude mice. I. Gross and light microscopic changes. J Toxicol Cutan Ocul Toxicol. 1984;3(4):371-91.

29. Vojvodic V, Milosavljević Z, Boskovic B, Bojanic N. The protective effect of different drugs in rats poisoned by sulfur and nitrogen mustards. Fundam Appl Toxicol. 1985;5(6part2):S160-8

30. Papirmeister B, Feister AJ, Robinson SI, Ford RD. The sulphur mustard injury: Description of lesions and resulting incapacitation: Medical defence against mustard gas: Toxic mechanisms and pharmacological implications. Boca Raton, FL: CRC Press. 1991;13-34.

31. Goswami DG, Kumar D, Tewari-Singh N, Orlicky DJ, Jain AK, Kant R, et al. Topical nitrogen mustard exposure causes systemic toxic effects in mice. Experimental and Toxicologic Pathology. 2015;67(2):161-70.

32. Sawale SD, Ambhore PD, Pawar PP, Pathak U, Deb U, Satpute RM. Ameliorating effect of S-2 ( $\omega$-aminoalkylamino) alkylaryl sulfide (DRDE-07) on sulfur mustard analogue, 2-chloroethyl ethyl sulfide-induced oxidative stress and inflammation. Toxicology Mechanisms and Methods. 2013;23(9):702-10.

33. Yue L, Zhang Y, Chen J, Zhao Z, Liu Q, Wu R, et al. Distribution of DNA adducts and corresponding tissue damage of Sprague-Dawley rats with percutaneous exposure to sulfur mustard. Chem. R Toxicol. 2015;28(3):532-40.

34. Drent M, Cobben NA, Henderson RF, Wouters EF, Dieijen-Visser MV. Usefulness of lactate dehydrogenase and its isoenzymes as indicators of lung damage or inflammation. European Respiratory Journal. 1996;9(8):1736-42.
35. Guth DJ, Mavis RD. The effect of lung a-tocopherol content on the acute toxicity of nitrogen dioxide. Toxicology and Applied Pharmacology. 1986;84(2):304-14.

36. McCabe AJ, Dowhy M, Holm BA, Glick PL. Myeloperoxidase activity as a lung injury marker in the lamb model of congenital diaphragmatic hernia. Journal of Pediatric Surgery. 2001;36(2):334-7.

37. Fu P, Birukova AA, Xing J, Sammani S, Murley JS, Garcia JG, et al. Amifostine reduces lung vascular permeability via suppression of inflammatory signalling. European Respiratory Journal. 2009;33(3):612-24.

38. Chakrabarti S, Patel KD. Matrix metalloproteinase-2 (MMP-2) and MMP-9 in pulmonary pathology. Experimental Lung Research. 2005;31(6):599-621.

39. Calvet JH, Planus E, Rouet P, Pezet S, Levame M, Lafuma C, et al. Matrix metalloproteinase gelatinases in sulfur mustard-induced acute airway injury in guinea pigs. Ame J Physio Lung Cellular and Mol Physiol. 1999; 276(5):L754-62.

40. Allon N, Amir A, Manisterski E, Rabinovitz I, Dachir S, Kadar T. Inhalation exposure to sulfur mustard in the guinea pig model: Clinical, biochemical and histopathological characterization of respiratory injuries. Toxicol and A Pharmacol. 2009;241(2):154-62.

41. Korkmaz A, Yaren H, Topal T, Oter S. Molecular targets against mustard toxicity: Implication of cell surface receptors, peroxynitrite production and PARP activation. Archives of Toxicol. 2006;80(10):662-70.

42. Anderson DR, Yourick JJ, Arroyo CM, Young GD, Harris LW. Use of EPR spintrapping techniques to detect radicals from rat lung lavage fluid following sulfur mustard vapor exposure. Army Medical Research Inst of Chemical Defense Aberdeen Proving Ground Md. 1993.

43. Kelly FJ. Gluthathione: In defence of the lung. Food Chem Toxicol. 1999;37(910):963-6.

44. Goa KL, Spencer CM. Amifostine: A review of its pharmacodynamoc and pharmacokinetic protperties and therapeutic potential as a radioprotector and cuytotoxic chemoprotector. Drugs. 1995;50:1001-31.

45. Bhutia YD, Vijayaraghavan R, Pathak U. Analgesic and anti-inflammatory activity of amifostine, DRDE-07 and their analogs, in mice. IJP. 2010;42(1):17.

46. Beigi HA, Tahmasbpour E, Borna H, Imamy A, Ghanei M, Shahriary A. Free radical production and oxidative stress in lung tissue of patients exposed to sulfur mustard: An overview of cellular and molecular mechanisms. Chemical Research in Toxicology. 2018;31(4):211-22.

47. DeNeve WJ, Everett CK, Suminski JE, Valeriote FA. Influence of WR2721 on DNA cross-linking by nitrogen mustard in normal mouse bone marrow and leukemia cells in vivo. Cancer Research. 1988;48(21):6002-5.

48. Schlezinger JJ, White RD, Stegeman JJ. Oxidative inactivation of cytochrome P-450 1A (CYP1A) stimulated by 3, 3', 4, 4'-tetrachlorobiphenyl: Production of reactive oxygen by vertebrate CYP1As. Mol Pharmacol. 1999;56(3):588-97.

49. Vijayan V, Pathak U, Meshram GP. Mutagenicity and antimutagenicity studies of DRDE-07 and its analogs against sulfur mustard in the in vitro Ames Salmonella/microsome assay. Mutation Research/Genetic Toxicol Environ Mutagen. 2014;773:39-45

Cite this article: Soni AK, Pathak U, Nagar DP, Gupta AK, Kannan GM. Comparative Pulmonary Protective Efficacy of Amifostine and its Analogue S-2(2-aminoethylamino) ethyl Phenyl Sulfide (DRDE-07) against Sulphur Mustard Induced Oxidative Stress and Inflammation in Female Mice. Int. J. Pharm. Investigation. 2020;10(1):37-42. 